\title{
Research on resonance vibration simulation method of high-speed railway vehicle carbody
}

\author{
Yi-Zhao NIE ${ }^{\mathrm{a}}$, Jing Zeng ${ }^{\mathrm{b}}$, Fan-Song $\mathrm{LI}^{\mathrm{c}}$ \\ Southwest Jiaotong University, No.111, North 1st Section of Second Ring Road, Chengdu City, \\ Sichuan Province, China \\ anieyizhao@163.com, bvehicle@home.swjtu.edu.cn, ${ }^{\mathrm{c} l i f a n s o n g 2013 @ 163 . c o m ~}$
}

Keywords: railway vehicle, carbody, resonance vibration, rigid-flexible

\begin{abstract}
A three dimensional rigid-flexible coupled vehicle system dynamics model was built to simulate the vibration response of carbody, and the short wave of track spectrum was considered during simulation. Before the simulation, the finite element model (FEM) and substructure modal analysis of carbody was completed by ABAQUS software, the vehicle system dynamics model was established by SIMPACK software, and the short wave of track spectrum was modified by line test vibration data. Two concerned positions of carbody underframe, which located separately in middle of side beam and center of underframe, was chosen to verify the results from theoretical model and line test. The comparison results illustrate that rigid-flexible coupled model combined with track short wave effect could be used to simulate the resonance vibration of carbody appropriately.
\end{abstract}

\section{Introduction}

Weight reduction of railway vehicle has greatly contributed to speed-up. However, lightweight of car body often lead to less structural stiffness. From these reasons, the flexible vibration of car body need to be considered during vehicle system dynamics simulation.

In recent years, many experts utilize different vehicle dynamics model to study the vibration characteristics of car body. P.F. CARLBOM gives a method to combine multi-body system (MBS) with FEM for rail vehicle dynamics analysis[1]; P.B. Wu et al evaluate dynamic response of high-speed passenger car considered flexible car body model[2]; M. NAGAI et al use the flexible car body dynamics model to simulate the coupled vibration of passenger and lightweight car body, during the simulation, every passenger is modelled as one degree-of-freedom system[3]; $\mathrm{T}$. TOMIOKA et al provide a new method to calculate car body service weight modal, in the method, a car body is modeled as a box-type structure consisting of plates and beam, and then combine the MBS and FEM model to simulate the vibration of car body[4].

The conventional ride quality and running comfort computing method does not consider the flexible effect of car body, which is acceptable when the concerned positions do not contain local resonance vibration. However, when the local resonance vibration generated in the underframe of car body, the rigid multi-body dynamics method may produce large error. Among the references mentioned above, no one considers the high frequency $(20 \sim 40 \mathrm{~Hz})$ vibration of car body, a method to simulate high frequency is provided in this paper, which combines the rigid-flexible coupled model and short wave effect of track spectrum. The concerned frequency range of ride quality is shown in Figure 1 [5], so the max frequency considered in this paper is $40 \mathrm{~Hz}$.

\section{Rigid-flexible coupled modeling approach}

The flexible body in dynamics is described in Figure 2 in [6], $\mathbf{r}^{i p}=\mathbf{R}^{i}+\mathbf{A}^{i} \overline{\mathbf{u}}^{i p}=\mathbf{R}^{i}+\mathbf{A}^{i} \cdot\left(\overline{\mathbf{u}}_{o}^{p}+\overline{\mathbf{u}}_{f}^{p}\right)$

Where $\mathbf{r}^{i p}$ position vector of point $\mathrm{P}$ in global coordinate system;

$\overline{\mathbf{u}}^{i p}$ — position vector of point $\mathrm{P}$ in floating coordinate system;

$\mathbf{A}^{i}$ — orientation matrix of flexible body relative to global coordinate system; 
$\overline{\mathbf{u}}_{o}^{p} —$ displacement of point $\mathrm{P}$ rigid movement;

$\overline{\mathbf{u}}_{f}^{p} \_$flexible deformation of point P relative to floating coordinate system.
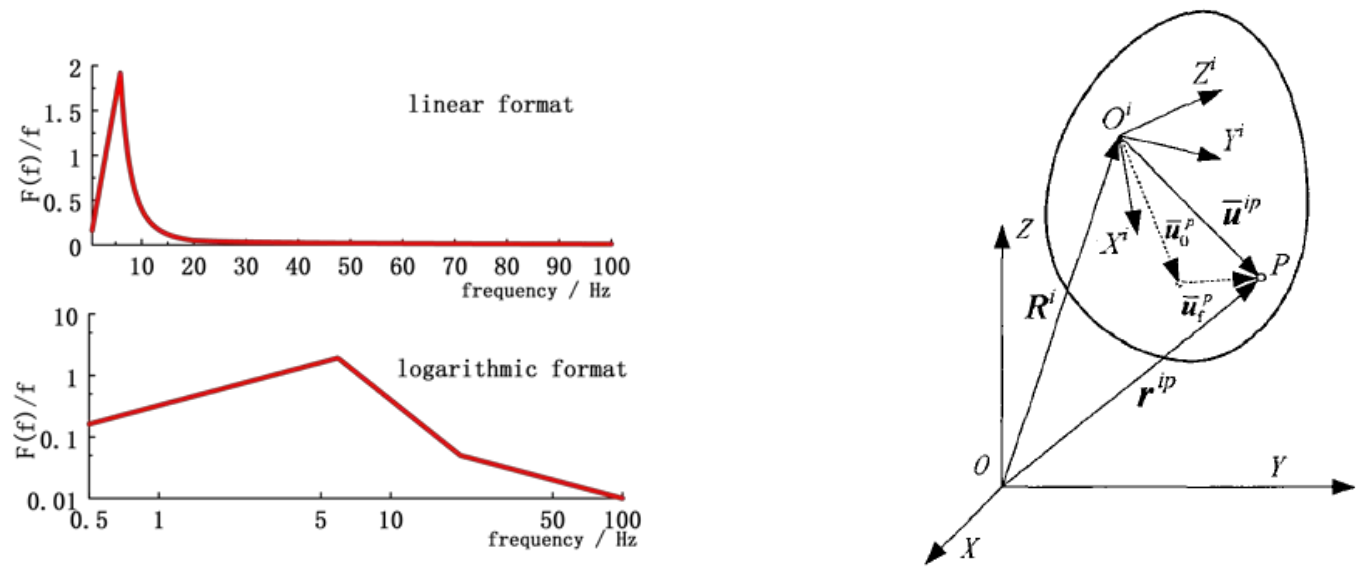

Figure 1. Concerned frequency range of ride quality Figure 2. Description of flexible body

The process of modeling a flexible carbody is shown in Figure 3, which mainly consists of three steps. The first step is to set up carobody FEM model with service weight, and generate the substructure model of carbody by ABAQUS, then produce the intermediate file for SIMPACK; the second step is to translate the intermediate file into SID format file for SIMPACK; the last step is to import the SID file and set the parameters in SIMPACK.

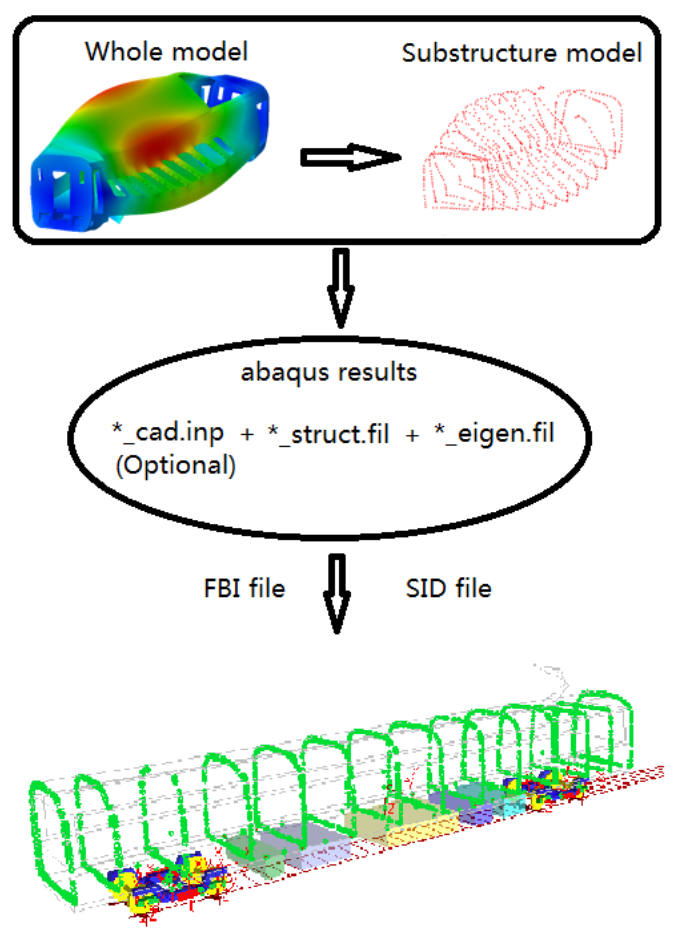

Figure 3. Process of establishing rigid-flexible multi-body dynamics model Table 1. Calculation error between whole DOF model and substructure model

\begin{tabular}{cccc}
\hline Mode & Whole model & Substructure model & Error \\
\hline 1 & 10.187 & 10.201 & $0.14 \%$ \\
\hline 2 & 11.479 & 11.550 & $0.62 \%$ \\
\hline 3 & 14.644 & 14.788 & $0.98 \%$ \\
\hline 4 & 15.008 & 15.121 & $0.75 \%$ \\
\hline 5 & 15.327 & 15.373 & $0.30 \%$ \\
\hline 6 & 17.337 & 17.047 & $1.67 \%$ \\
\hline
\end{tabular}

The use of substructure should be emphasized in the preprocessor. The basic idea of substructure is to consider a substructure separately and eliminate all but the degrees of freedom needed to concern in the whole model. So the calculation errors between substructure model and whole degree of 
freedom model is given in Table 1 . The maximum error is $1.67 \%$ in the sixth mode, therefore, the substructure model meets the engineering requirements.

\section{Short wave of track spectrum}

The measured track excitation of Beijing-Tianjin line (JJ spectrum) is used to simulate the influence of track irregularity. The original JJ spectrum is shown in Figure 4. During the simulation, the original track spectrum add a track spectrum with short waves. Then excitation between wheel and rail contains the short wave effects. The power spectral density of track irregularity is [7]

$S(f)=k \cdot 0.036 f^{-3.15}$

Where $f$ is the spatial frequency $[1 / \mathrm{m}], k$ is scale factor of irregularity.

The random frequency ranges $20 \sim 40 \mathrm{~Hz}$, considered in this paper. Figure 4 shows the time domain and frequency domain of the short wave.
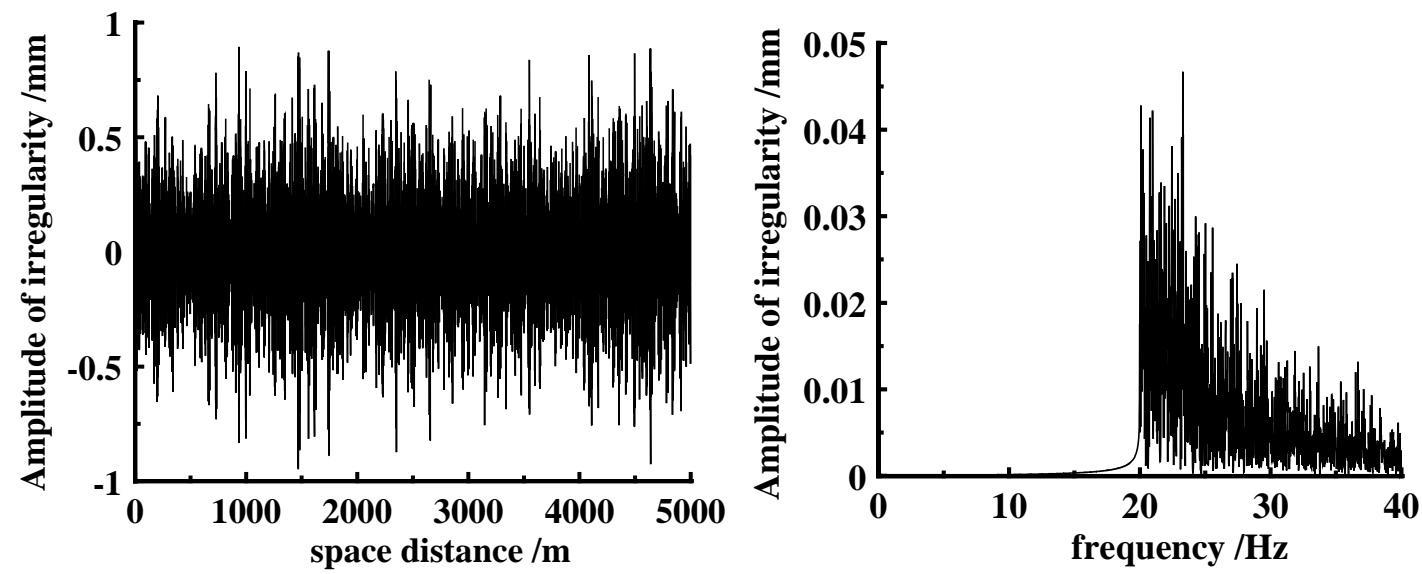

Figure 4. The track spectrum of short wave

\section{Rigid-flexible coupled vehicle system dynamics model}

A three-dimensional rigid-flexible coupled vehicle system dynamics model established for high-speed coach by ABAQUS and SIMPACK shows in Figure 5. The primary suspension is modeled as parallel spring-damper elements, and the nonlinear wheel-rail contact are considered. Air springs, yaw dampers, lateral stops, anti-roll bars, lateral dampers and traction links are considered in secondary suspension system. In addition, all of the equipment are mounted on the underframe according to the actual parameters in the dynamics model.

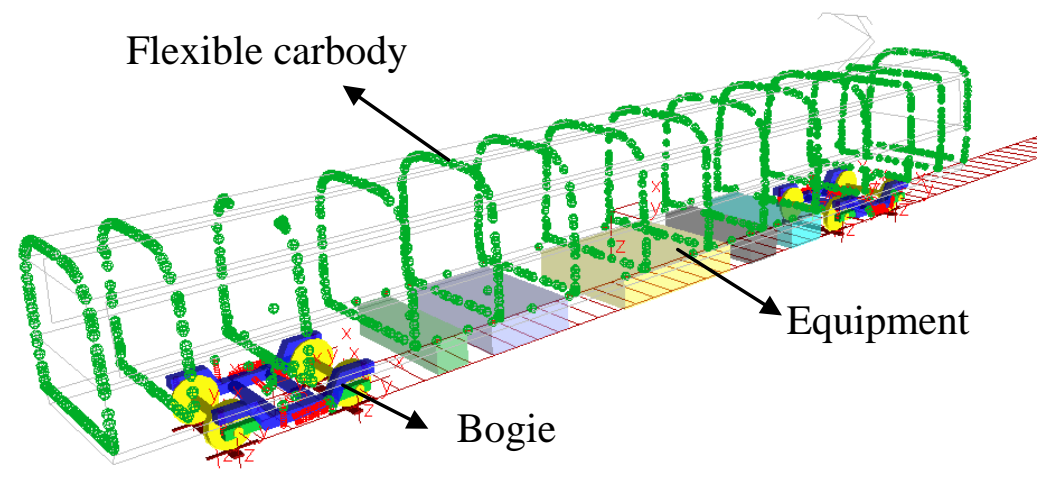

Figure 5. A three-dimensional rigid-flexible coupled vehicle system dynamics model

\section{Vibration simulation results of carbody}

Four MBS models, considering effects of flexible carbody and short wave separately, are used to simulate the vibration characteristics of underframe. The four MBS models are rigid model with or 
without short wave effect and rigid-flexible coupled model with or without short wave effect. During the simulation, two positions are concerned, which is located in the middle of side beam (point A) and the center of underframe (point B) separately.

The simulation results of concerned positions are shown in figure 6 and figure 7 . From figure 6 , we could find that a rigid multi-body dynamics model is not sensitive to short wave excatation, while the rigid-flexible coupled model does. Especially when the concerned position contains local resonance, the rigid multi-body dynamics model could not give a right result.

From figure 7, the conclusionwe can be given that the rigid-flexible coupled model could obtain better results around the flexible resonance frequency. At higher frequency, the vibration characteristic of point $A$ is different from that of point $B$, this is beacase the vibration amplitude at point $\mathrm{A}$ is much smaller than that of point $\mathrm{B}$. The vibration characteristics at high frequency relate to the system input excitation.

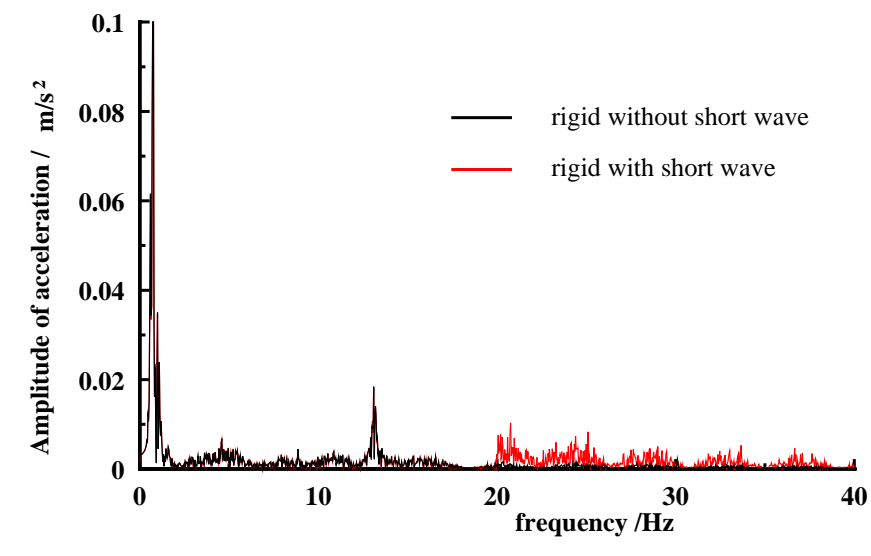

(a) Short wave effect of rigid model

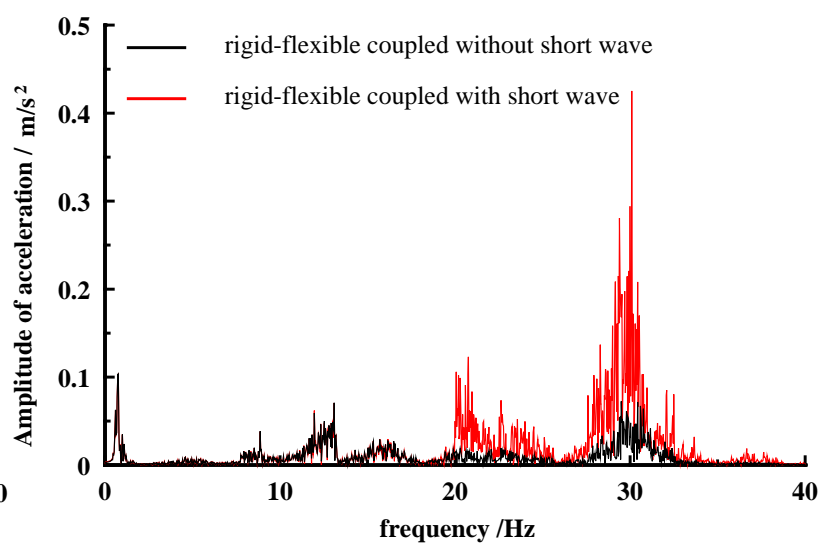

(b) Short wave effect of rigid-flexible coupled model

Figure 6. Vibration simulation results of point b

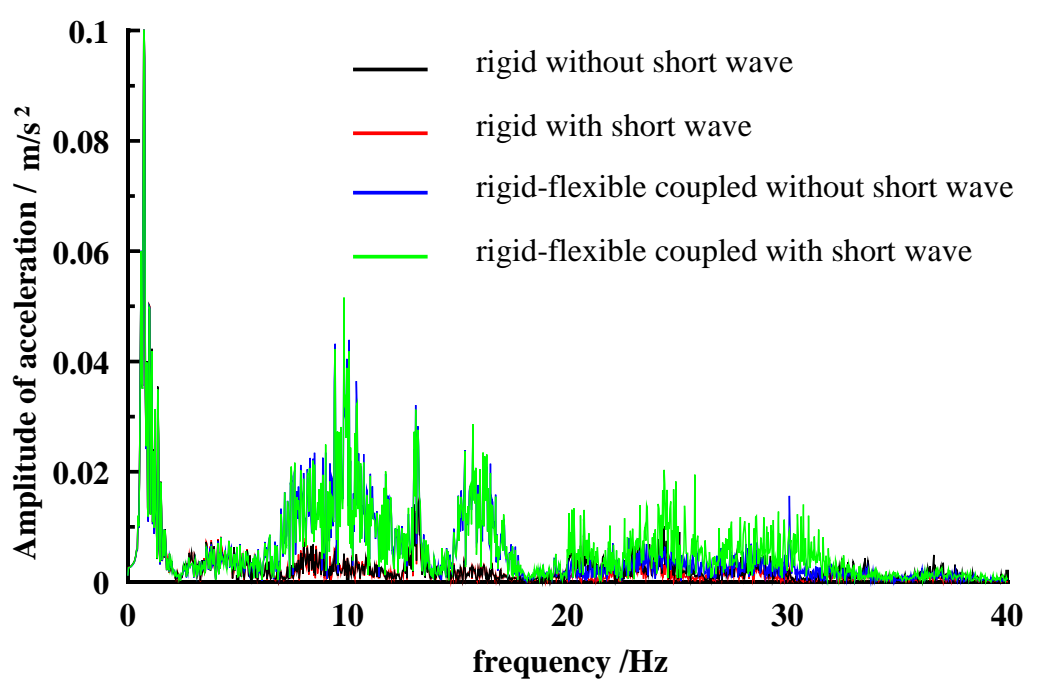

Figure 7. Vibration simulation results of point a

From figure 8, the rigid-flexible coupled model with track short wave could give a satisfactory result, the local resonance frequency of underframe fitting better with line test result. However, the amplitude simulation method needs further study. 


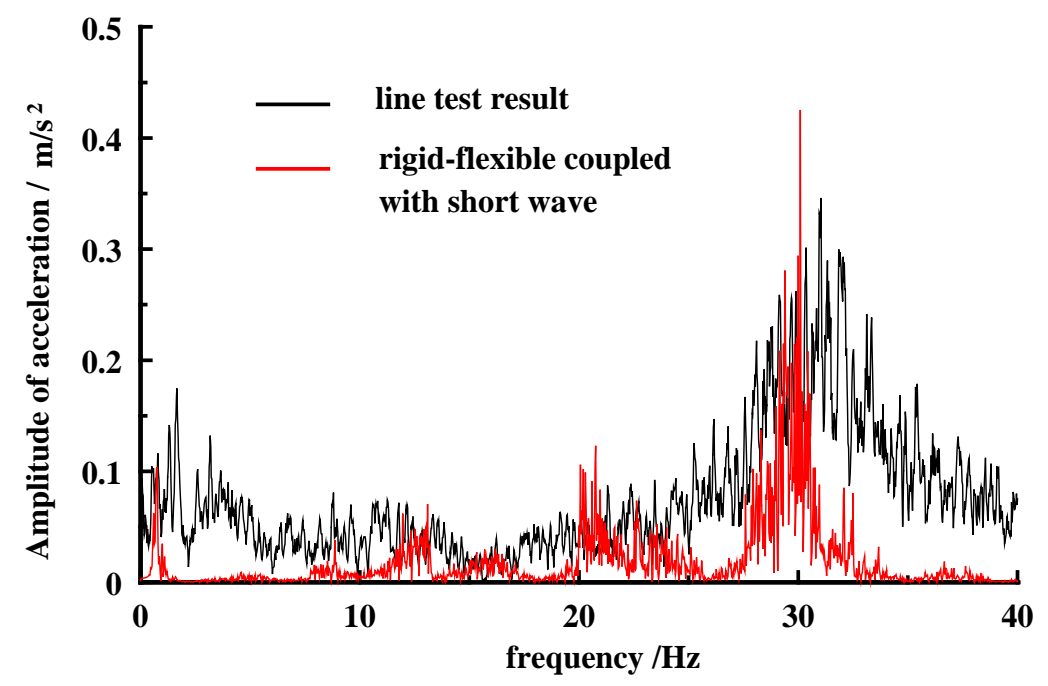

Figure 8. Comparison between line test result and simulation result at point $b$

\section{Summary}

(1) When local resonance vibration generated at the concerned position, the resonance vibration should be considered during simulation. However, the rigid multi-body dynamics model could not give satisfactory results.

(2) Rigid-flexible coupled dynamics model and track spectrum with short wave are effective means to simulate the local flexible resonance, even though the resonance frequency is high.

(3) The more accurate simulation method of high-frequecy vibration needs further study, specially the vibration amplitude.

\section{Acknowledgement}

This research was financially supported by the National High-tech R\&D Program of China [2012AA112001-02], the National Natural Science Fund of China [U1334206], and the railway ministry science and technology research and development program [2012G002].

\section{References}

[1] P.F. CARLBOM. Combining MBS with FEM for Rail Vehicle Dynamics Analysis. Multibody System Dynamics, vol.6, 291-300 (2001)

[2] P.B. Wu, S.H. Xue, C.H. Yang. Dynamic response of high-speed passenger car based on flexible car body model. Journal of Traffic and Transportation Engineering, vol.5, p. 5-8 (2005)

[3] M. NAGAI, H.YOSHIDA, T. TOHTAKE and Y. SUZUKI. Coupled vibration of passenger and lightweight car-body in consideration of human-body biomechanics. Vehicle System Dynamics, vol.44, p. 601-611 (2006)

[4] T. TOMIOKA, T. TAKIGAMI and Y. SUZUKI. Numerical analysis of three-dimensional flexural vibration of railway vehicle car body. Vehicle System Dynamics, vol.44, 272-285 (2006)

[5] GB 5599-1985. Railway vehicles - Specification for evaluation the dynamic performance and accreditation test (1985)

[6] H. Gao. Study on rigid-flexible coupling dynamic simulation method and platform for railway vehicle. Southwest Jiaotong University doctoral academic dissertation (2013)

[7] L. Wang, M.C. YAO. Random vibration theory of railtrack structure and it's application in the study of railtrack vibration isolation. China Railway Science, vol.2, $41-59$ (1989) 